\title{
GMR
}

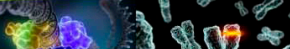

\section{Ursodeoxycholic acid upregulates ERK and Akt in the protection of cardiomyocytes against $\mathrm{CoCl}_{2}$}

\author{
N.I. Hanafi ${ }^{1}$, A.S. Mohamed ${ }^{1}$, J. Md Noor ${ }^{2}$, N. Abdul Hamid Hasani ${ }^{2}$, \\ R. Siran' ${ }^{2}$, N.J. Osman' ${ }^{2}$ S. Ab Rahim ${ }^{2}$ and S.H. Sheikh Abdul Kadir ${ }^{1,2}$ \\ ${ }^{1}$ Institute of Medical Molecular Biotechnology, Faculty of Medicine, \\ Universiti Teknologi MARA, Jalan Hospital, Sungai Buloh, Selangor, \\ Malaysia \\ ${ }^{2}$ Faculty of Medicine, Universiti Teknologi MARA, Jalan Hospital, \\ Sungai Buloh, Selangor, Malaysia \\ Corresponding author: S.H. Sheikh Abdul Kadir \\ E-mail: sitih587@salam.uitm.edu.my
}

Genet. Mol. Res. 15 (2): gmr.15028150

Received November 26, 2015

Accepted April 15, 2016

Published June 17, 2016

DOI http://dx.doi.org/10.4238/gmr.15028150

ABSTRACT. Ursodeoxycholic acid (UDCA) is used to treat liver diseases and demonstrates cardioprotective effects. Accumulation of the plasma membrane sphingolipid sphingomyelin in the heart can lead to atherosclerosis and coronary artery disease. Sphingomyelinases (SMases) break down sphingomyelin, producing ceramide, and inhibition of SMases activity can promote cell survival. We hypothesized that UDCA regulates activation of ERK and Akt survival signaling pathways and SMases in protecting cardiac cells against hypoxia. Neonatal cardiomyocytes were isolated from 0- to 2-day-old Sprague Dawley rats, and given $100 \mu \mathrm{M} \mathrm{CoCl}_{2}, 150 \mu \mathrm{M} \mathrm{H}_{2} \mathrm{O}_{2}$, or placed in a hypoxia chamber for $24 \mathrm{~h}$. The ameliorative effects of $100-\mu \mathrm{M}$ UDCA treatment for $12 \mathrm{~h}$ were then assessed using MTS, QuantiGene Plex (for Smpd1 and Smpd2), and SMase assays, beating rate assessment, and western blotting (for ERK and Akt). Data were analyzed by the 
paired Student $t$-tests and one-way analyses of variance. Cell viability decreased significantly after $\mathrm{H}_{2} \mathrm{O}_{2}(85 \%), \mathrm{CoCl}_{2}(50 \%)$, and hypoxia chamber $(52 \%)$ treatments compared to the untreated control $(100 \%)$. UDCA significantly counteracted the effects of chamber- and $\mathrm{CoCl}_{2}-$ induced hypoxia on viability and beating rate. However, no significant differences were observed in acid SMase gene and protein expression between the untreated, $\mathrm{CoCl}_{2}$, and UDCA-CoCl 2 groups. In contrast, neutral SMase gene and protein expression did significantly differ between the latter two groups. ERK and Akt phosphorylation was higher in hypoxic cardiomyocytes treated with UDCA than those given $\mathrm{CoCl}_{2}$ alone. In conclusion, UDCA regulates the activation of survival signaling proteins and SMases in neonatal rat cardiomyocytes during hypoxia.

Key words: Cardiomyocytes; Hypoxia; Ursodeoxycholic acid; Sphingomyelinases

\section{INTRODUCTION}

Bile acids play an important role in digestion and the absorption of fats in the small intestine. In addition, these amphiphatic molecules perform physiological functions in glucose metabolism and immune responses (Hylemon et al., 2009). Recently, they have also been recognized as signaling molecules in human colon cancer cells (Von Rosenvinge and Raufman, 2011), hepatocytes (Amaral et al., 2009), and cardiomyocytes (Sheikh Abdul Kadir et al., 2010). The most hydrophilic bile acid, ursodeoxycholic acid (UDCA), is synthesized in the small intestine. UDCA represents only approximately $1-3 \%$ of the bile acids present in the human body. Practitioners of Chinese traditional medicine have been using UDCA as a remedy for hepatic diseases and other liver-related disorders for more than 1000 years (Beuers, 2006). Currently, UDCA is used to treat various cholestatic disorders, such as intrahepatic cholestasis of pregnancy, cholelithiasis (Perez and Briz, 2009), and primary sclerosing cholangitis (Paumgartner and Beuers, 2004). Its application as a drug to treat non-liver diseases, including colon carcinoma (Im and Martinez, 2004), Alzheimer's disease (Amaral et al., 2007), and glaucoma (Boatright et al., 2009) has been considered and widely studied. This bile acid has also been reported to have beneficial effects in cardiovascular disease (Lee et al., 1999). Miragoli et al. (2011) demonstrated that UDCA protects cardiomyocytes against the arrhythmogenic effects of the more hydrophobic bile acid taurocholate (TC).

The sphingolipid signaling cascade is important in maintaining sphingolipid metabolism and regulating cell fate via ceramide production. Sphingomyelinases (SMases), which hydrolyze sphingomyelin into ceramide and phosphorylcholine, are the key enzymes in sphingolipid metabolism, and are divided into three major types: acid SMase (aSMase), neutral SMase (nSMase), and alkaline SMase. During stress, outer membrane sphingomyelin is exposed to the action of aSMase. Subsequently, nSMase is activated and hydrolyzes inner membrane sphingomyelin, producing ceramide. Ceramide is known to be a second messenger in deciding whether cells implement proliferation or apoptosis signaling (Okada et al., 2009). In mediating such pathways, ceramide re-synthesis in the cytosol is crucial for the production of phospholipase $\mathrm{C}$ and activation of diacylglycerol signaling, such as in the regulation of 
intracellular calcium and phosphorylation of Akt and MAP kinases. Studies suggest that the site of its production by SMases is the key factor determining ceramide's cellular function. In cardiomyocytes, nSMase activity is elevated during the early stage of hypoxia-reoxygenation (Hernandez et al., 2000). Furthermore, stimulation of nSMase has been shown to be connected to factor associated with neutral sphingomyelinase activation in cardiac cell death. It has been demonstrated that reduced sphingomyelin production inhibits atherosclerosis and contributes to the amelioration of certain cardiovascular diseases (Glaros et al., 2007).

SMases are reported to be active during hypoxia in PC12 during neurite formation induced by the nerve growth factor (Yoshimura et al., 1999), artery smooth muscle cells (Cogolludo et al., 2009), and hepatocytes (Zhu et al., 2012). Yoshimura et al. (1999) found that nSMase is inhibited during hypoxic death of PC12 cells pretreated with glutathione. In chronic heart failure, lack of glutathione synthesis leads to nSMase activation (Adamy et al., 2007). Both SMases play significant roles in cells. aSMase is involved in apoptosis, such as that induced by inflammatory cytokine signaling during retinal microangiopathy in diabetic patients (Opreanu et al., 2011). In cardiomyocytes, nSMase has been reported to be activated as part of the cellular response to hypoxia-reoxygenation. UDCA has been proposed as a candidate drug for the treatment of cardiac diseases and the protection of cells from further damage caused by recurrent ischemia. A previous study involving chronic heart failure patients showed that UDCA treatment improves peripheral blood flow (von Haehling et al., 2012). However, its mechanism of action remains poorly understood. Therefore, we aimed to investigate the involvement of the extracellular signal-regulated kinase (ERK) and Akt cell survival signaling pathways and SMases in UDCA-mediated cardioprotection.

\section{MATERIAL AND METHODS}

Procedures involving animals were conducted with the approval of the Research Committee on Ethical of Animal Use in Research (UiTM Care - 99/2015). For cell culture, all medium and supplements were purchased from GIBCO, USA. Briefly, primary neonatal rat cardiomyocytes were treated with UDCA before or after hypoxia challenge. To induce hypoxia, cells were treated with $\mathrm{CoCl}_{2}$ or placed in a hypoxia chamber for $24 \mathrm{~h}$. Then cells were exposed to UDCA for $12 \mathrm{~h} . \mathrm{H}_{2} \mathrm{O}_{2}$, a known an agent that induced hypoxia, was used to compare its effects with $\mathrm{CoCl}_{2}$ and hypoxia chamber. In order to study the effects of UDCA signaling, cells were subjected for $\mathrm{G}_{\mathrm{i}}$-sensitive pathway using inhibitor known as pertussin toxin (PTX) treatment and agonist of S1P receptor known as fingolimod (FTY720). In order to further examine our hypothesis that the protection of cardiomyocytes against hypoxia by UDCA affects SMases, ERK, and Akt, cells were collected for western blotting and QuantiGene Plex and SMase assays. This study was carried out to clarify the mechanism by which UDCA protects cardiac cells against hypoxia.

\section{Primary culture of neonatal rat ventricular myocytes}

Neonatal cardiomyocytes were isolated from 0-2-day-old Sprague Dawley rats. In brief, left ventricles were minced and serially digested with $0.03 \%$ collagenase and $0.03 \%$ trypsin. Cells were repeatedly washed and pre-plated to remove non-myocytes. The isolated myocytes were then cultured for 12-18 h on gelatin-coated dishes in Dulbecco's modified Eagle's medium containing 10\% fetal bovine serum. Hypoxia was induced for $24 \mathrm{~h}$ using a 
chamber or chemicals $\left(\mathrm{CoCl}_{2}\right.$ or $\left.\mathrm{H}_{2} \mathrm{O}_{2}\right)$. Cells were treated with $100 \mu \mathrm{M}$ UDCA after exposure of hypoxia. While only for Smases assays, $100 \mu \mathrm{M}$ UDCA were either given before exposure of hypoxia (UDCA- $\left.\mathrm{CoCl}_{2}\right)$ or after exposure of hypoxia $\left(\mathrm{CoCl}_{2}-\mathrm{UDCA}\right)$.

\section{Cell viability assay}

The CellTiter $96 \mathrm{AQ}_{\text {ueous }}$ One Solution Cell Proliferation MTS Assay (Promega, Fitchburg, WI, USA) was used to measure cell viability. Cells (500 000 cells $/ \mathrm{mL})$ were grown on 96-well plates and then cell were treated at different concentrations $(50,100,200$, and $250 \mu \mathrm{M})$ of UDCA. CellTiter $96 \mathrm{AQ}_{\text {ueous }}$ One Solution reagent $(20 \mu \mathrm{L})$ was added to each well. The 96 -well plates were then placed in a $5 \% \mathrm{CO}_{2}$ incubator at $37^{\circ} \mathrm{C}$ for $1 \mathrm{~h}$, before absorbance at $490 \mathrm{~nm}$ was measured.

\section{Beating assessment}

The beating assessment was performed according to the method described by Clark et al. (1991), involving visual recording using an Olympus (Tokyo, Japan) inverted fluorescence microscope. A random location near the center of each culture was observed, and an area a cell demonstrating a typical rhythmic movement was identified. A stopwatch was used to measure the time taken for 20 beats, which was then converted to the number of beats per minute (bpm). A single field of each culture was recorded daily. To eliminate bias, multiple readings from the same culture were performed and the beating frequencies of several cells from each culture were recorded. If no contraction was observed in the selected field for $30 \mathrm{~s}$, that culture was recorded as being negative for beating.

\section{SMase assays}

An Amplex Red Sphingomyelinase Assay Kit (Life Technologies, Carlsbad, CA, USA) was used to detect levels of neutral, $\mathrm{pH}$ 7.0, and acidic, $\mathrm{pH}$ 5.0, SMases, which are reported to be highly expressed in cardiomyocytes (He et al., 2002). SMase activity was assayed in vitro by labeling cells with fluorescent derivatives. Assay mixtures were incubated for $30 \mathrm{~min}$ at $37^{\circ} \mathrm{C}$ prior to detection. Fluorescence was measured at 560 and $590 \mathrm{~nm}$ excitation and emission wavelengths, respectively. Fluorescence intensity is expressed in relative fluorescence units (RFU).

\section{QuantiGene Plex assay}

Untreated (control) and treated cardiomyocytes were stored at $-80^{\circ} \mathrm{C}$ prior to analysis. QuantiGene Plex (version 2.0; Affymetrix, Santa Clara, CA, USA) amplification involves the quantitative measurement of fluorescence from multiple RNA targets. This technique allows for the simultaneous direct measurement of eight RNAs of interest in cultured cells. Fluorescence associated with sphingomyelin phosphodiesterase 1 ( $S m p d 1)$, sphingomyelin phosphodiesterase 2 (Smpd2), and the housekeeping genes Gapdh, Hprt1, and Gusb was then detected using a Luminex flow cytometer (Luminex Corporation, Austin, TX, USA) and is reported as median fluorescence intensity (MFI). This technology uses fluorescent microspheres (beads) to quantify specific RNA targets by employing different probe sets. Gene expression was calculated and is presented as fold changes induced by each treatment compared to the control. 


\section{Western blotting}

Protein samples were collected after UDCA treatment. Treated cells were lysed with Pierce radioimmunoprecipitation assay lysis buffer (Thermo Scientific, Waltham, MA, USA) containing protease inhibitor. Lysates were then processed by sodium dodecyl sulfate-polyacrylamide gel electrophoresis. Proteins were quantified using the Bradford assay (Thermo Scientific), resolved on a 10\% Bis-Tris gel, and transferred to a nitrocellulose membrane. The membrane was then blocked for $1 \mathrm{~h}$ at room temperature with $5 \%$ bovine serum albumin and washed with $1 \mathrm{X}$ phosphate-buffered saline-Tween-20 buffer, before being incubated with anti-Akt and -ERK primary antibodies (Cell Signaling Technology, Danvers, MA, USA) for $24 \mathrm{~h}$ at $4^{\circ} \mathrm{C}$. Immunoreactive bands were detected using anti-immunoglobulin $\mathrm{G}$ secondary antibodies and chemiluminescence reagents (Thermo Scientific). Immunoblots were visualized using X-ray film.

\section{Statistical analysis}

Statistical analyses were performed using SPSS version 20.0 (IBM Corp., Armonk, NY, USA). Values are reported as means \pm standard errors of the mean. Data were tested for normality with the Kolmogorov-Smirnov test, and assessed using one-way analysis of variance or the paired Student's t-test. P values $<0.05$ were considered significant.

\section{RESULTS}

\section{UDCA protects cell viability against the effects of $\mathrm{H}_{2} \mathrm{O}_{2}$ and $\mathrm{CoCl}_{2}-$ and chamber- induced hypoxia}

In comparison to untreated cells $(100 \%)$, cardiomyocyte viability was not significantly changed by UDCA treatment $(102 \pm 12.37 \% ; \mathrm{P}=0.4)$. However, compared to the untreated group, $\mathrm{H}_{2} \mathrm{O}_{2}(85 \pm 6.21 \% ; \mathrm{P}=0.005)$ and $\mathrm{CoCl}_{2}-(50 \pm 11.76 \% ; \mathrm{P}=0.003)$ and chamberinduced hypoxia $(52 \pm 3.79 \% ; \mathrm{P}=0.03)$ did affect viability. UDCA significantly improved the viability of cells exposed to $\mathrm{CoCl}_{2}(92 \pm 16.23 \% ; \mathrm{P}=0.02)$ and the hypoxia chamber $(93 \pm$ $12.88 \% ; \mathrm{P}=0.04)$, but did not protect cells against $\mathrm{H}_{2} \mathrm{O}_{2}(69 \pm 10.00 \% ; \mathrm{P}=0.1)$. These results show that UDCA protects against hypoxia induced by $\mathrm{CoCl}_{2}$ or a low-oxygen atmosphere, but does not prevent the effects of $\mathrm{H}_{2} \mathrm{O}_{2}$ on cell viability (Figure 1).

\section{UDCA maintains the beating rate of $\mathrm{CoCl}_{2}$-induced hypoxic cardiomyocytes}

The beating rate of cardiomyocytes treated with $100 \mu \mathrm{M} \mathrm{CoCl}_{2}$ was reduced to $68 \%(37 \pm 1.33 \mathrm{bpm} ; \mathrm{P}=0.02)$ of that observed with untreated cells $(53 \pm 1.76 \mathrm{bpm})$. Administration of UDCA alone had no effect on beating rate $(52 \pm 1.16 \mathrm{bpm} ; \mathrm{P}=0.06$ compared to the $\mathrm{CoCl}_{2}$ hypoxia group). Cardiomyocytes incubated with UDCA appeared to be protected against the effects of $\mathrm{CoCl}_{2}(63 \pm 1.20 \mathrm{bpm} ; \mathrm{P}=0.01$ compared to treatment with $\mathrm{CoCl}_{2}$ alone). Statistically significant differences were recorded at $\mathrm{P}<0.05$, with $\mathrm{N} \geq$ 3. These findings indicate that UDCA treatment protects cardiomyocytes against $\mathrm{CoCl}_{2}-$ induced hypoxia (Figure 2). 


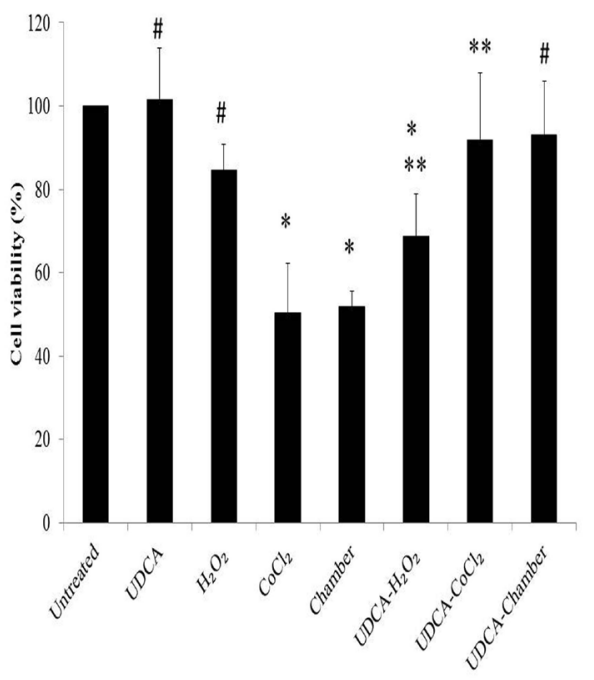

Figure 1. Ursodeoxycholic acid (UDCA) counteracted the effect of $\mathrm{CoCl}_{2}$ on cardiomyocyte viability. $\mathrm{CoCl}_{2}$ reduced cardiomyocyte viability by approximately $50 \%$ (means \pm standard error of the mean: $50 \pm 11.76 \% ; \mathrm{P}=$ $0.003)$ compared to untreated cells $(100 \%)$. Administration of UDCA $(92 \pm 16.23 \% ; \mathrm{P}=0.02)$ significantly rescued the decrease in viability caused by $\mathrm{CoCl}_{2}$ and hypoxia chamber treatments. Statistically significant differences were recorded at $\mathrm{P}<0.05$ using one-way analysis of variance based on at least three independent observations. Significant differences are represented as follows: *against untreated; **against $\mathrm{CoCl}_{2}$ alone; *against hypoxia chamber treatment.

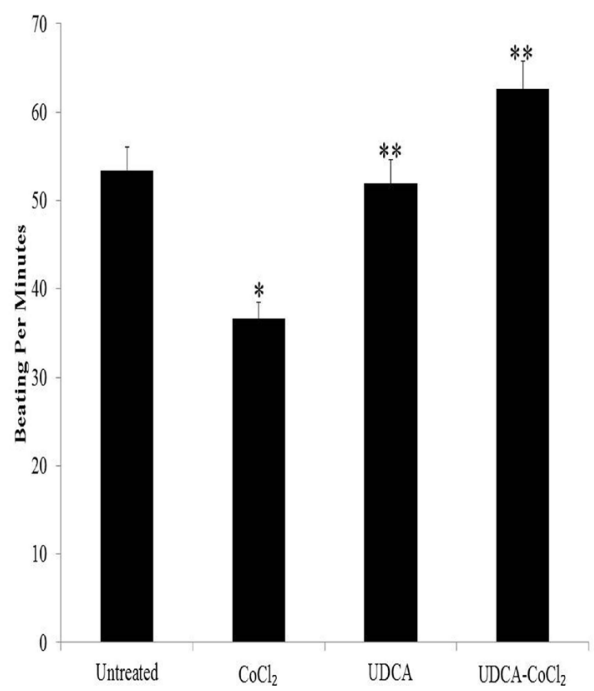

Figure 2. Ursodeoxycholic acid (UDCA) prevented the effect of $\mathrm{CoCl}_{2}$ on cardiomyocyte beating rates. $\mathrm{CoCl}_{2}$ reduced cardiomyocyte beating rate to $68 \%$ (mean \pm standard error: $37 \pm 1.33 \mathrm{bpm} ; \mathrm{P}=0.02$ ) of that observed with untreated cells $(53 \pm 1.76 \mathrm{bpm})$. Cardiomyocytes treated with UDCA and $\mathrm{CoCl}_{2}$ showed significantly increased beating rates $(63 \pm 1.20 \mathrm{bpm} ; \mathrm{P}=0.01)$ compared to $\mathrm{CoCl}_{2}$ treatment only. Statistically significant differences were recorded at $\mathrm{P}<0.05$ using the paired sample $t$-test based on at least three independent observations. Significant differences are represented as follows: *against untreated; **against $\mathrm{CoCl}_{2}$ alone. 


\section{Involvement of SMases in UDCA cardioprotection against $\mathrm{CoCl}_{2}$}

$\mathrm{CoCl}_{2}$-treated cardiomyocytes exhibited similar aSMase level $(14,724 \pm 7412$ $\mathrm{RFU})$ with untreated cardiomyocytes $(15,025 \pm 3704 \mathrm{RFU})$. For $n \mathrm{nSMase}, \mathrm{CoCl}_{2}$-treated cardiomyocytes $(19,546 \pm 2307)$ and UDCA-treated cardiomyocytes $(22,549 \pm 9179 \mathrm{RFU})$ showed increased of expression compared to untreated cardiomyocytes $(13,839 \pm 3209 \mathrm{RFU}$; $\mathrm{P}<0.05$ ). Interestingly, administration of UDCA- $\mathrm{CoCl}_{2}$ resulted in reduced nSMase activity (nSMase: 13,533 $\pm 2791 \mathrm{RFU}$ ) compared to treatment with $\mathrm{CoCl} 2$ alone. While no significant differences were observed in aSMase between UDCA-CoCl $2(16,240 \pm 2663 \mathrm{RFU})$ and $\mathrm{CoCl}_{2}$ alone $(14,724 \pm 7412 \mathrm{RFU})$. This seems to suggest that the protection against $\mathrm{CoCl}_{2}$ conferred by UDCA does involve regulation of SMases (Figure 3). Regarding the corresponding RNA transcripts, cardiomyocytes treated with UDCA-CoCl 2 showed increased Smpd2 (nSMase gene) levels (1.355 MFI) but no difference in Smpd1 (aSMase gene) expression compared to those given only $\mathrm{CoCl}_{2}$ (Figure 4).

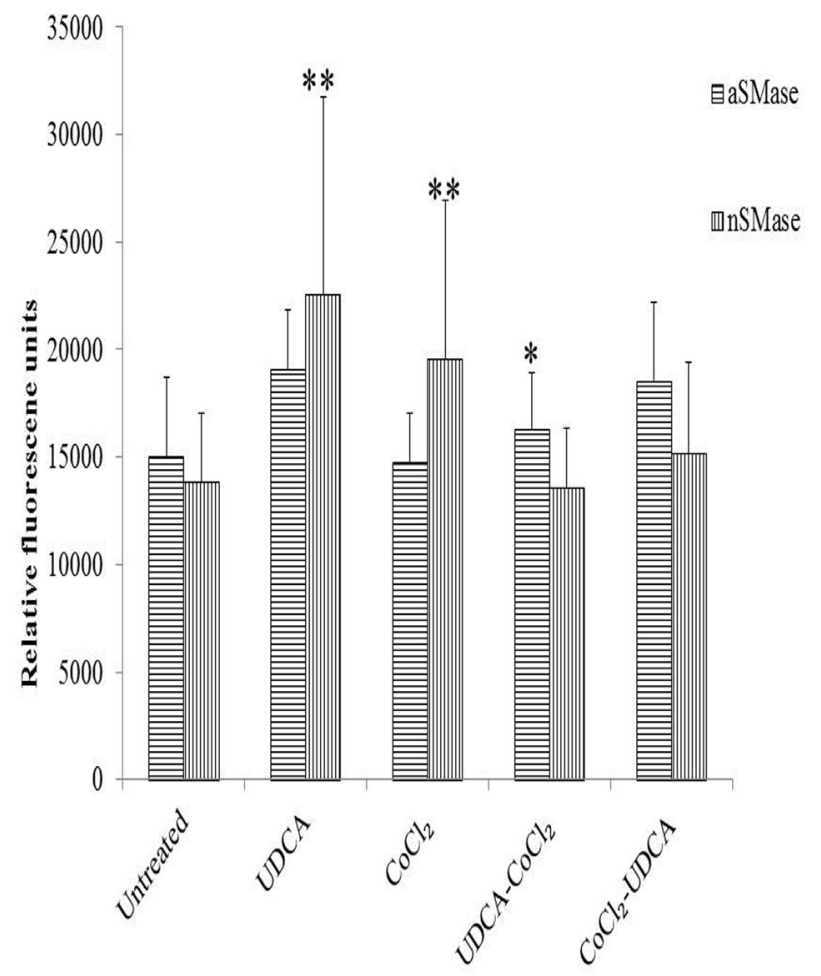

Figure 3. Ursodeoxycholic acid (UDCA) downregulated neutral sphingomyelinase (nSMase) in $\mathrm{CoCl}_{2}$-treated cardiomyocytes. Higher levels of acid sphingomyelinase [aSMase; mean \pm standard error of the mean: 15,025 \pm 3704 relative fluorescence units (RFU)] than nSMase (13,839 $\pm 3209 \mathrm{RFU})$ were measured in untreated cardiomyocytes. Cells treated with only UDCA showed a significant increase in nSMase $(22,549 \pm 9179 \mathrm{RFU})$ compared to aSMase $(19,064 \pm 2750)$. In $\mathrm{CoCl}_{2}$-treated cells, elevated nSMase $(19,546 \pm 2307)$ was observed in comparison to aSMase $(14,724 \pm 7412)$, in contrast to untreated cells. Statistically significant differences were recorded at $\mathrm{P}<0.05$ using the paired sample $t$-test based on at least three independent observations. Significant differences are represented as follows: *against $\mathrm{CoCl}_{2}$; **against untreated. 


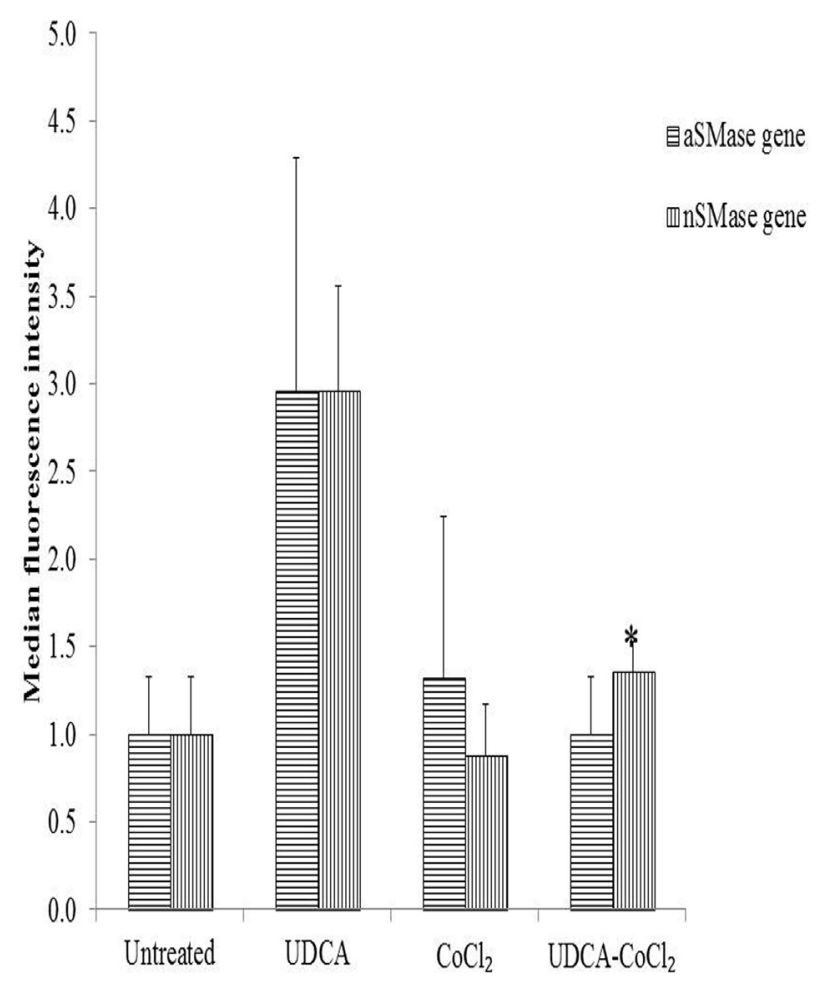

Figure 4. Ursodeoxycholic acid (UDCA) regulated sphingomyelinase gene expression. Expression of Smpdl was upregulated in $\mathrm{CoCl}_{2}$-treated cardiomyocytes compared to that of $\mathrm{Smpd2}$. Administration of $\mathrm{CoCl}_{2}$-treated cells with UDCA appeared to increase Smpd2 levels. Statistically significant differences were recorded at $\mathrm{P}<0.05$ using the paired sample $t$-test based on at least three independent observations. *Significantly different compared to $\mathrm{CoCl}_{2}$.

\section{UDCA activates ERK and $\mathrm{Akt}$ in $\mathrm{CoCl}_{2}$-treated cardiomyocytes}

Further experiments were carried out to investigate the involvement of ERK and Akt in UDCA's amelioration of the effects of $\mathrm{CoCl}_{2}$ on cardiomyocytes. Phosphorylation of ERK and Akt was decreased in $\mathrm{CoCl}_{2}$-treated cardiomyocytes compared to the UDCA-CoCl${ }_{2}$ group. No significant difference was detected in the expression of total ERK and total Akt between the $\mathrm{CoCl}_{2}$ and untreated groups. However, upregulation was observed in cells administered UDCA-CoCl . Expression of ERK and Akt was not inhibited by PTX; thus, it does not block the effect of UDCA (Figure 5A and B).

\section{DISCUSSION}

Hypoxia, the presence of low oxygen levels during cellular metabolism, can affect vascular tone and $\mathrm{Na}^{+}$and $\mathrm{Ca}^{2+}$ ion channels. Cardiomyocytes adapt to hypoxic environments by increasing apoptosis inhibitor gene expression and reducing mitochondrial function 


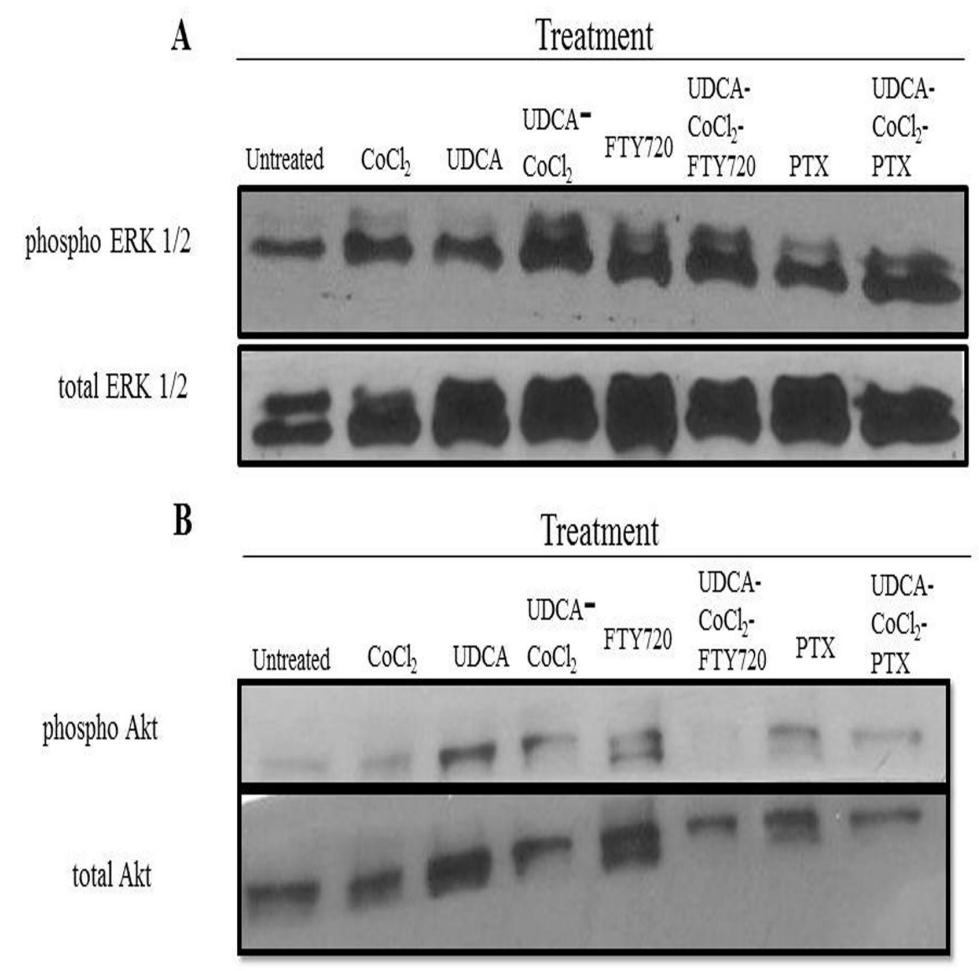

Figure 5. Treatment with ursodeoxycholic acid (UDCA) upregulated ERK and Akt expression in $\mathrm{CoCl}_{2}$-treated cardiomyocytes. A. ERK expression significantly increased in cardiomyocytes treated with UDCA-CoCl ${ }_{2}$ compared to those given UDCA-CoCl 2 only. B. Akt expression was low in $\mathrm{CoCl}_{2}$-treated cells compared to those administered UDCA-CoCl ${ }_{2}$. Statistically significant differences were recorded at $\mathrm{P}<0.05$ using the paired sample $t$-test based on at least three independent observations. phospho $=$ phosphorylated.

(Kakinuma et al., 2008). The effects of chemically induced hypoxia can be achieved by treating cells with deferoxamine (Guo et al., 2006) or dimethyloxalylglycine (Elvidge et al., 2006). Here, hypoxia was induced using a hypoxia chamber or $\mathrm{CoCl}_{2}$ (Dai et al., 2012). Previous studies have reported that these methods have a similar effect on cells in creating a low-oxygen environment. Consistent with this, we showed that both chamber- and $\mathrm{CoCl}_{2}$-induced hypoxic cardiomyocytes exhibited significant reductions in viability and beating rate (Figures 1 and 2). Interestingly, these effects were not observed in cells treated with UDCA. UDCA, the most hydrophilic bile acid, has been shown to protect cardiomyocytes from hypoxia (Rajesh et al., 2005). $\mathrm{CoCl}_{2}$-induced hypoxia causes changes in cardiomyocyte electrophysiology $(\mathrm{Ng}$ et al., 2011), but UDCA seems to improve the beating rate of $\mathrm{CoCl}_{2}$-treated cells. Gorelik et al. (2002) and Miragoli et al. (2011) revealed that UDCA protects cardiomyocytes against the effects of TC on their contraction. Treatment with $\mathrm{H}_{2} \mathrm{O}_{2}$ appears to have a less notable effect on viability than chamber- or $\mathrm{CoCl}_{2}$-induced hypoxia. Chen et al. (2000) reported that $\mathrm{H}_{2} \mathrm{O}_{2}$ causes the death of $\mathrm{H} 9 \mathrm{C} 2$ cells and primary neonatal rat cardiomyocytes by apoptosis at a concentration of $200 \mu \mathrm{M}$ or lower. However, Gülden et al. (2010) showed that the cytotoxicity of $\mathrm{H}_{2} \mathrm{O}_{2}$ depends on incubation time and cell concentration. 
Lithocholic acid-induced cholestatic liver disease occurs due to disrupted sphingolipid homeostasis mediated by nSMase (Matsubara et al., 2011). In colon cancer cells, UDCA inhibits cell growth by regulating the expression of nSMase (Liu et al., 2006). SMases are essential enzymes in the breakdown of sphingomyelin into ceramide in response to cellular stress, such as hypoxia. Plasma membrane sphingomyelin is involved in a number of activities, including signal transduction and cell polarization. UDCA has been shown to inhibit the arrhythmogenic effects of TC by affecting the membrane potential of myofibroblasts in the heart (Miragoli et al., 2011). Moreover, accumulation of ceramide in the post-ischemic heart has been associated with aSMase activity (Klevstig et al., 2016). However, the effect of UDCA on increased SMase levels in cardiomyocytes is not well known. In the present work, UDCA-CoCl, treatment led to a reduction in nSMase protein expression compared to the administration of $\mathrm{CoCl}_{2}$ alone (Figure 3). Meanwhile, changes in aSMase activity were not significant. Smpdl gene expression in $\mathrm{CoCl}_{2}$-induced hypoxic cells was upregulated compared to that in untreated cardiomyocytes, but the UDCA-CoCl and untreated groups did not significantly differ in this respect. A significant difference in Smpd2 expression was observed between the UDCA-CoCl ${ }_{2}$ and $\mathrm{CoCl}_{2}$ groups (Figure 4).

ERK is a mitogen-activated protein kinase known to promote cell survival through inhibition of p53 activation in breast cancer cells (Rieber and Strasberg-Rieber, 2014). During hypoxia, epidermal growth factor receptor-dependent ERK and Akt activation are thought to coincide with the eventual outcome of cell death signaling (Xu et al., 2006). The Akt signaling pathway plays a role in cardiomyocyte survival during intermediate and severe hypoxia (Rajesh et al., 2005). Akt is the downstream effector of the activated form of a phosphatidylinositol 3-kinase subunit, and has been shown to play a role in myocyte contractility (Shiojima et al., 2012). Activation of these survival pathways in rat hepatocytes has been reported to inhibit apoptosis (Qiao et al., 2002). Yuan et al. (2012) described the involvement of ERK phosphorylation in nitric oxide-maintained $\mathrm{X}$-linked inhibitor of apoptosis protein levels during hypoxia/reoxygenation in cardiomyocytes. Here, $\mathrm{CoCl}_{2}$-induced hypoxic cardiomyocytes demonstrated reduced ERK and Akt protein phosphorylation compared to UDCA-CoCl $\mathrm{C}_{2}$ Moreover, upregulation of phosphorylated ERK and Akt was observed in $\mathrm{CoCl}_{2}$-induced hypoxic cells treated with UDCA (Figures 5A and 5B). Egom et al. (2011) demonstrated that upon Akt activation, sphingosine-1phosphate is released as part of the cardiomyocyte protection mechanism.

In summary, we have demonstrated that UDCA protects hypoxic cardiomyocytes by regulating ERK and Akt phosphorylation. Our findings suggest that UDCA counteracts the effects of $\mathrm{CoCl}_{2}$ on cardiomyocyte viability, contractility, nSMase upregulation, and survival signaling. Our observations show that UDCA may play a significant role in protecting heart cells from $\mathrm{CoCl}_{2}$-induced hypoxia.

\section{CONCLUSIONS}

We found UDCA to be involved in Akt and ERK survival pathway activation. Furthermore, this study provides an insight into UDCA's cardioprotective effects in hypoxia, and the involvement of elevated nSMase expression.

\section{Conflicts of interest}

The authors declare no conflict of interest. 
Ursodeoxycholic acid protects cardiomyocytes against $\mathrm{CoCl}_{2}$

\section{ACKNOWLEDGMENTS}

The authors would like to express their sincere appreciation to members of the Institute of Medical Molecular Biotechnology (IMMB) and the Laboratory Animal Care Unit (LACU), Faculty of Medicine, Universiti Teknologi MARA (UiTM). This study was supported by the Malaysian Ministry of Higher Education: Fundamental Research Grant Scheme (FRGS) FRGS 5/3/FST(47/2011), and the Research Acculturation Grant Scheme (600-RMI/RAGS/2012/ UITM/ST04/1) and (RAGS/1/2014/SKK01/UITM/1).

\section{REFERENCES}

Adamy C, Mulder P, Khouzami L, Andrieu-abadie N, et al. (2007). Neutral sphingomyelinase inhibition participates to the benefits of $\mathrm{N}$-acetylcysteine treatment in post-myocardial infarction failing heart rats. J. Mol. Cell. Cardiol. 43: 344-353. http://dx.doi.org/10.1016/j.yjmcc.2007.06.010

Amaral JD, Castro RE, Solá S, Steer CJ, et al. (2007). p53 is a key molecular target of ursodeoxycholic acid in regulating apoptosis. J. Biol. Chem. 282: 34250-34259. http://dx.doi.org/10.1074/jbc.M704075200

Amaral JD, Viana RJ, Ramalho RM, Steer CJ, et al. (2009). Bile acids: regulation of apoptosis by ursodeoxycholic acid. J. Lipid Res. 50: 1721-1734. http://dx.doi.org/10.1194/j1r.R900011-JLR200

Beuers U (2006). Drug insight: Mechanisms and sites of action of ursodeoxycholic acid in cholestasis. Nat. Clin. Pract. Gastroenterol. Hepatol. 3: 318-328. http://dx.doi.org/10.1038/ncpgasthep0521

Boatright JH, Nickerson JM, Moring AG and Pardue MT (2009). Bile acids in treatment of ocular disease. J. Ocul. Biol. Dis. Infor. 2: 149-159. http://dx.doi.org/10.1007/s12177-009-9030-x

Chen QM, Tu VC, Wu Y and Bahl JJ (2000). Hydrogen peroxide dose dependent induction of cell death or hypertrophy in cardiomyocytes. Arch. Biochem. Biophys. 373: 242-248. http://dx.doi.org/10.1006/abbi.1999.1558

Clark WA, Rudnick SJ, LaPres JJ, Lesch M, et al. (1991). Hypertrophy of isolated adult feline heart cells following betaadrenergic-induced beating. Am. J. Physiol. 261: C530-C542.

Cogolludo A, Moreno L, Frazziano G, Moral-Sanz J, et al. (2009). Activation of neutral sphingomyelinase is involved in acute hypoxic pulmonary vasoconstriction. Cardiovasc. Res. 82: 296-302. http://dx.doi.org/10.1093/cvr/cvn349

Dai ZJ, Gao J, Ma XB, Yan K, et al. (2012). Up-regulation of hypoxia inducible factor-1 $\alpha$ by cobalt chloride correlates with proliferation and apoptosis in PC-2 cells. J. Exp. Clin. Cancer Res. 31: 1-8. http://dx.doi.org/10.1186/1756-9966-31-28

Egom EE, Mohamed TM, Mamas MA, Shi Y, et al. (2011). Activation of Pak1/Akt/eNOS signaling following sphingosine1-phosphate release as part of a mechanism protecting cardiomyocytes against ischemic cell injury. Am. J. Physiol. Heart Circ. Physiol. 301: H1487-H1495. http://dx.doi.org/10.1152/ajpheart.01003.2010

Elvidge GP, Glenny L, Appelhoff RJ, Ratcliffe PJ, et al. (2006). Concordant regulation of gene expression by hypoxia and 2-oxoglutarate-dependent dioxygenase inhibition: the role of HIF-1alpha, HIF-2alpha, and other pathways. J. Biol. Chem. 281: 15215-15226. http://dx.doi.org/10.1074/jbc.M511408200

Glaros EN, Kim WS, Wu BJ, Suarna C, et al. (2007). Inhibition of atherosclerosis by the serine palmitoyl transferase inhibitor myriocin is associated with reduced plasma glycosphingolipid concentration. Biochem. Pharmacol. 73: 1340-1346. http://dx.doi.org/10.1016/j.bcp.2006.12.023

Gorelik J, Harding SE, Shevchuk AI, Koralage D, et al. (2002). Taurocholate induces changes in rat cardiomyocyte contraction and calcium dynamics. Clin. Sci. 103: 191-200. http://dx.doi.org/10.1042/cs1030191

Gülden M, Jess A, Kammann J, Maser E, et al. (2010). Cytotoxic potency of H2O2 in cell cultures: impact of cell concentration and exposure time. Free Radic. Biol. Med. 49: 1298-1305. http://dx.doi.org/10.1016/j.freeradbiomed.2010.07.015

Guo M, Song LP, Jiang Y, Liu W, et al. (2006). Hypoxia-mimetic agents desferrioxamine and cobalt chloride induce leukemic cell apoptosis through different hypoxia-inducible factor-1alpha independent mechanisms. Apoptosis 11: 67-77. http://dx.doi.org/10.1007/s10495-005-3085-3

He X, Chen F, McGovern MM and Schuchman EH (2002). A fluorescence-based, high-throughput sphingomyelin assay for the analysis of Niemann-Pick disease and other disorders of sphingomyelin metabolism. Anal. Biochem. 306: 115-123. http://dx.doi.org/10.1006/abio.2002.5686

Hernandez OM, Discher DJ, Bishopric NH and Webster KA (2000). Rapid activation of neutral sphingomyelinase by hypoxia-reoxygenation of cardiac myocytes. Circ. Res. 86: 198-204. http://dx.doi.org/10.1161/01.RES.86.2.198

Hylemon PB, Zhou H, Pandak WM, Ren S, et al. (2009). Bile acids as regulatory molecules. J. Lipid Res. 50: 1509-1520. http://dx.doi.org/10.1194/jlr.R900007-JLR200 
Im E and Martinez JD (2004). Ursodeoxycholic acid (UDCA) can inhibit deoxycholic acid (DCA)-induced apoptosis via modulation of EGFR/Raf-1/ERK signaling in human colon cancer cells. J. Nutr. 134: 483-486.

Kakinuma Y, Katare RG, Arikawa M, Muramoto K, et al. (2008). A HIF-1alpha-related gene involved in cell protection from hypoxia by suppression of mitochondrial function. FEBS Lett. 582:332-340. http://dx.doi.org/10.1016/j.febslet.2007.12.026

Klevstig M, Ståhlman M, Lundqvist A, Scharin Täng M, et al. (2016). Targeting acid sphingomyelinase reduces cardiac ceramide accumulation in the post-ischemic heart. J. Mol. Cell. Cardiol. 93: 69-72. http://dx.doi.org/10.1016/j. yjmcc.2016.02.019

Lee WY, Han SH, Cho TS, Yoo YH, et al. (1999). Effect of ursodeoxycholic acid on ischemia/reperfusion injury in isolated rat heart. Arch. Pharm. Res. 22: 479-484. http://dx.doi.org/10.1007/BF02979156

Liu F, Cheng Y, Wu J, Tauschel HD, et al. (2006). Ursodeoxycholic acid differentially affects three types of sphingomyelinase in human colon cancer Caco 2 cells. Cancer Lett. 235: 141-146. http://dx.doi.org/10.1016/j.canlet.2005.04.016

Matsubara T, Tanaka N, Patterson AD, Cho JY, et al. (2011). Lithocholic acid disrupts phospholipid and sphingolipid homeostasis leading to cholestasis in mice. Hepatology 53: 1282-1293. http://dx.doi.org/10.1002/hep.24193

Miragoli M, Kadir SH, Sheppard MN, Salvarani N, et al. (2011). A protective antiarrhythmic role of ursodeoxycholic acid in an in vitro rat model of the cholestatic fetal heart. Hepatology 54: 1282-1292. http://dx.doi.org/10.1002/hep.24492

$\mathrm{Ng} \mathrm{KM}$, Chan YC, Lee YK, Lai WH, et al. (2011). Cobalt chloride pretreatment promotes cardiac differentiation of human embryonic stem cells under atmospheric oxygen level. Cell. Reprogram. 13: 527-537.

Okada T, Kajimoto T, Jahangeer S and Nakamura S (2009). Sphingosine kinase/sphingosine 1-phosphate signalling in central nervous system. Cell. Signal. 21: 7-13. http://dx.doi.org/10.1016/j.cellsig.2008.07.011

Opreanu M, Tikhonenko M, Bozack S, Lydic TA, et al. (2011). The unconventional role of acid sphingomyelinase in regulation of retinal microangiopathy in diabetic human and animal models. Diabetes 60: 2370-2378. http://dx.doi. org $/ 10.2337 / \mathrm{db} 10-0550$

Paumgartner G and Beuers U (2004). Mechanisms of action and therapeutic efficacy of ursodeoxycholic acid in cholestatic liver disease. Clin. Liver Dis. 8: 67-81, vi. http://dx.doi.org/10.1016/S1089-3261(03)00135-1

Perez MJ and Briz O (2009). Bile-acid-induced cell injury and protection. World J. Gastroenterol. 15: 1677-1689. http:// dx.doi.org/10.3748/wjg.15.1677

Qiao L, Yacoub A, Studer E, Gupta S, et al. (2002). Inhibition of the MAPK and PI3K pathways enhances UDCA-induced apoptosis in primary rodent hepatocytes. Hepatology 35: 779-789. http://dx.doi.org/10.1053/jhep.2002.32533

Rajesh KG, Suzuki R, Maeda H, Yamamoto M, et al. (2005). Hydrophilic bile salt ursodeoxycholic acid protects myocardium against reperfusion injury in a PI3K/Akt dependent pathway. J. Mol. Cell. Cardiol. 39: 766-776. http:// dx.doi.org/10.1016/j.yimcc.2005.07.014

Rieber M and Strasberg-Rieber M (2014). p53 inactivation decreases dependence on estrogen/ERK signalling for proliferation but promotes EMT and susceptility to 3-bromopyruvate in ER $\alpha+$ breast cancer MCF-7 cells. Biochem. Pharmacol. 88: 169-177. http://dx.doi.org/10.1016/j.bcp.2014.01.025

Sheikh Abdul Kadir SH, Miragoli M, Abu-Hayyeh S, Moshkov AV, et al. (2010). Bile acid-induced arrhythmia is mediated by muscarinic M2 receptors in neonatal rat cardiomyocytes. PLoS One 5: e9689. http://dx.doi.org/10.1371/ journal.pone.0009689

Shiojima I, Schiekofer S, Schneider JG, Belisle K, et al. (2012). Short-term akt activation in cardiac muscle cells improves contractile function in failing hearts. Am. J. Pathol. 181: 1969-1976. http://dx.doi.org/10.1016/j.ajpath.2012.08.020

Von Haehling S, Schefold JC, Jankowska E, Springer J, et al. (2012). Ursodeoxycholic acid in patients with chronic heart failure: a double-blind, randomized, placebo-controlled, crossover trial. J. Am. Coll. Cardiol. 59: 85-92.

Von Rosenvinge EC and Raufman JP (2011). Muscarinic receptor signaling in colon cancer. Cancers (Basel) 3: 971-981. http://dx.doi.org/10.3390/cancers3010971

Xu D, Patten RD, Force T and Kyriakis JM (2006). Gene 33/RALT is induced by hypoxia in cardiomyocytes, where it promotes cell death by suppressing phosphatidylinositol 3-kinase and extracellular signal-regulated kinase survival signaling. Mol. Cell. Biol. 26: 5043-5054. http://dx.doi.org/10.1128/MCB.02387-05

Yoshimura S, Banno Y, Nakashima S, Hayashi K, et al. (1999). Inhibition of neutral sphingomyelinase activation and ceramide formation by glutathione in hypoxic PC12 cell death. J. Neurochem. 73: 675-683. http://dx.doi.org/10.1046/ j.1471-4159.1999.0730675.x

Yuan H, Yan B, Wang HH, Hua S, et al. (2012). Nitric oxide preserves XIAP and reduces hypoxia/reoxygenation-induced cardiomyocytes apoptosis via ERK1/2 activation. Biochem. Biophys. Res. Commun. 421: 134-139. http://dx.doi. org/10.1016/j.bbrc.2012.03.138

Zhu Q, Lin L, Cheng Q, Xu Q, et al. (2012). The role of acid sphingomyelinase and caspase 5 in hypoxia-induced HuR cleavage and subsequent apoptosis in hepatocytes. Biochim. Biophys. Acta 1821: 1453-1461. http://dx.doi. org/10.1016/j.bbalip.2012.08.005 